\title{
Development of an intelligent system for integrated management of hydroelectric cascade modes
}

\author{
$A G$ Rusina $^{1}, D z h K h$ Khudzhasaidov $^{2}, O V$ Naumov $^{3}$ and $A N$ Gorlov $^{4}$ \\ ${ }^{1}$ Novosibirsk State Technical University, Novosibirsk, Russia \\ ${ }^{2}$ Tajik Technical University, Tajikistan \\ ${ }^{3}$ Kazan State Power Engineering University, Kazan, Russia \\ ${ }^{4}$ The Southwest State University, Kursk, Russia
}

\begin{abstract}
The paper deals with an isolated electric power system (EPS) based on hydroelectric power plants. The analysis of the existing methods and approaches for investigation of modes of EPS which comprise hydroelectric power plants is presented. A mathematical model of a hydroelectric station cascade has been developed, which allows taking into account the hydraulic connection during calculation of electrical modes. A software tool for optimization the operating modes of hydroelectric power plants as part of the power system was developed. It uses redistribution the load between hydraulic units both inside the station and between hydroelectric complexes of cascade hydroelectric stations. The task of modeling power consumption and load graphs of EPS with specific properties, based on the application of artificial intelligence methods, is considered.
\end{abstract}

\section{Introduction}

Electric power systems (EPS), which contain hydroelectric power plants (HPPs) in their generating structures, are currently competitive power complexes. The characteristic features possessed by hydroelectric power plants play the decisive role. The question related to the task of HPPs optimization should be considered as system-wide and inextricably linked with the characteristic features of the entire fuel and energy complex (FEC).

\section{Object of study}

At present, Pamir Energy operates 11 hydroelectric power plants, of which Pamir-1 and Khorog HPPs are the larger ones, as well as 9 small hydropower plants with a total installed capacity of $43.5 \mathrm{MW}$. It is worth noting that small hydropower plants are characterized by insufficient water supply during the winter months. In this regard, hydropower plants, working to a given schedule and using the river's natural flow without redistribution in the daily context, cannot cover the load curve during periods of peak loads.

Uncertainty of processes, development of the system and the importance of taking into account the time factor in the absence of tools allowing decision-making while planning and managing the EPS modes results in the necessity for creation an imitation model. This model should allow one to carry out a series of simulation calculations taking into account the time factor and make decisions on the analysis and planning of normal electricity modes for a system of cascade of hydropower plants, to improve the efficiency of its operation.

\section{Model of the modes' optimization}

The power system of the Pamirs is a system in which $100 \%$ of electricity is generated by hydroelectric power stations, which makes it necessary to correct the mechanism of hydroelectric modes optimization in specific conditions. In such an energy system, fuel efficiency is a factor characterizing the efficient use of hydropower resource, i.e. the primary task is to optimally distribute the load between the system stations, while the natural variability and uncertainty of hydraulic processes are an objective reality. Thus, the amount of runoff and hydrograph cannot be affected, since this is a natural non-repeating process. If the domestic flow rate or the mode of usage the reservoir water resources changes, then the capability of hydroelectric power plants also changes. Thus, rational actions related to the optimal regime can lead to a significant increase in the production of electricity at hydropower plants. The composition of the main hydroelectric complex of the considered Pamir energy system is given in table 1 .

Characteristics of the units are presented in the form of consumption $Q_{i}=Q_{i}\left(N_{i}\right)$ or performance $\eta_{i}=\eta_{i}\left(N_{i}\right)$ at $H_{i}=$ const. Calculations are made according to the expenditure characteristics, if one knows the performance data, it is recalculated according to the formula:

\footnotetext{
* Corresponding author: 311670@ list.ru
} 
Table 1. Characteristics of HPPs of the main hydroelectric complex of the Pamir EPS.

\begin{tabular}{|c|l|c|c|c|c|}
\hline № & Name of HPP & $\begin{array}{c}\text { Installed power, } \\
\text { MW }\end{array}$ & $\begin{array}{c}\text { Number of } \\
\text { hydraulic units }\end{array}$ & $\begin{array}{c}\text { Calculated } \\
\text { head, } \mathbf{~ m}\end{array}$ & $\begin{array}{c}\text { Water consumption } \\
\text { through the unit, } \mathbf{~ m}^{\mathbf{3}} \mathbf{s}\end{array}$ \\
\hline 1 & Pamir-1 & 28 & 4 & 79.6 & 10.1 \\
\hline 2 & Khorog & 9 & 5 & 59 & 3.55 \\
\hline 3 & Namadhut & 2.5 & 2 & 36 & 3.5 \\
\hline
\end{tabular}

$$
Q_{i}=\frac{N_{i}}{9.81 \eta_{i} H} \text {, }
$$

In the program, this is analyzed by value $d$. With $d=0$, performance is converted to consumption. For other values of $d$, this conversion is not performed. Depending on the selected step $t$, the number of calculation points $l$ is calculated in the interval from power $P_{\min }$ to $P_{\max }$ of one unit:

$$
l=\frac{P_{\max }-P_{\min }}{t}+1,
$$

Depending on the obtained value $l$, the cost matrix of all aggregates $B[i, j]$ is calculated for all fixed power values, where $i$ is the unit number; $j$ is the number of power values.

For each power value, we select the unit, the flow of which is less:

$$
f_{i}\left(P_{S}\right)=\min \left\{Q_{i}\left(P_{i}\right)\right\},
$$

where $P_{\min } \leq P_{i} \leq P_{\max }, P_{\mathrm{s}}$ is the station load. The value $Q_{i}\left(N_{i}\right)$ is determined by the points of the characteristics of any unit consumption of which is minimum for the corresponding power value.

The calculation is performed starting from the minimum power station, which can be provided with two units to the maximum:

$$
2 N_{\min } \leq P_{S} \leq 2 N_{\max } .
$$

For each load value $P_{s}$ there is at least $f_{2}$, and the power of the second unit $P_{2}$ varies from $P_{\min }$ to $P_{\max }$ :

$$
f\left(P_{s}\right)=\min \left\{Q_{2}\left(N_{2}\right)+f_{1}\left(P_{s}-N_{2}\right)\right\} .
$$

The determination of the optimal station mode is carried out using the reverse procedure. So, for the known power station it is determined by the optimal composition of the units and their power, which is clearly shown in table 2 .
Table 2. The optimal mode of Pamir-1, with $H=79.6 \mathrm{~m}$.

\begin{tabular}{|c|c|c|c|c|c|}
\hline $\begin{array}{c}\text { Load stations } \\
N_{j}, \text { MW }\end{array}$ & \multicolumn{5}{|c|}{ Load of Units, MW } \\
\hline & 1 & 2 & 3 & 4 & $Q_{i}, \mathrm{~m}^{3} / \mathrm{s}$ \\
\hline $1-7$ & $1-7$ & - & - & - & $2.2-10.1$ \\
\hline $7.5-13.5$ & $4.5-6.5$ & $3-7$ & - & - & $11-19.4$ \\
\hline $14-18.5$ & $5-6.5$ & $5-6.5$ & $4-5.5$ & - & $20.09-26.685$ \\
\hline $19-27.5$ & $5-7$ & $5-7$ & $4-6.5$ & $5-7$ & $27.44-40.57$ \\
\hline 28 & 7 & 7 & 7 & 7 & 41.41 \\
\hline
\end{tabular}

The joint operation of hydroelectric stations depends on the degree of flow regulation, installed capacity, cascade location of stations with hydraulic connections, single location of hydroelectric power stations on various watercourses, equipment characteristics, etc. The task should be solved according to the criterion of maximum advantage of using all hydroelectric stations in the system, which requires consideration of their mutual influence. To distribute the load between the stations located in a cascade (Pamir-1 HPP and Khorog HPP), the dynamic programming method was also used, and the calculation results are presented in table 3.

Table 3. Load distribution between stations.

\begin{tabular}{|c|c|c|c|}
\hline $\begin{array}{c}\text { Load power, } \\
\text { MW }\end{array}$ & \multicolumn{2}{|c|}{ Stations load, MW } & $\begin{array}{c}\text { Water } \\
\text { consumption }\end{array}$ \\
\hline & Pamir-1 & Khorog & $\boldsymbol{Q}_{\boldsymbol{i}}, \mathbf{~ m}^{\mathbf{3}} / \mathbf{s}$ \\
\hline $1-15$ & 15 & 0 & $2.1-21$ \\
\hline 16 & 15 & 1 & 23 \\
\hline $17-20$ & $17-20$ & 0 & $24.3-28$ \\
\hline 21 & 20 & 1 & 30.1 \\
\hline $22-28$ & $22-28$ & 0 & $30.8-40.4$ \\
\hline $29-37$ & 28 & $1-9$ & $42.5-53.8$ \\
\hline
\end{tabular}

As it can be seen from table 3, when distributing the load between stations located in a cascade, for the effective use of hydro-resource, it is necessary to load the Pamir-1 HPP, since with such a distribution of load, it is possible to achieve the lowest water consumption.

To solve this problem, a software implementation of the "Optimization" block was created, which is based on the dynamic programming method. This unit is used in the work not only in terms of system and in-station optimization issues, but also during the simulation calculations of the normal modes of the power system. The block "Optimization" allows performing the distribution of load between the units of hydroelectric power plants in the automated mode, as well as to 
choose the composition of the units included in the operation.

\section{Modeling of electric consumption and load schedules of EPS}

The operation of electric power system as a whole depends on the accuracy of the energy balances. Load graphs in a power system are sequences of calculated values that reflect changes in power over a specific time interval. Over the years, the most common way to describe the process of power consumption is the time series. The change in daily, weekly and annual power consumption in this case is often modeled by dividing the time series into trend, periodic, and random components:

$$
X(t)=Q(t)+S(t)+U(t)
$$

where $Q(t)$ is the trend-steady systematic changes; $S(t)$ is the periodic component, i.e. fluctuations relative to the trend; $U(t)$ is the irregular component, i.e. random noise.

The initial information is data on electricity consumption (monthly average power values) for 8 years, in the periods from 2007-2011 and from 20142016 , i.e. there is some "gap" in the source data, which is an additional subject for assessment of the "sustainability" of the considered modeling methods. Analysis, modeling and forecasting of power consumption in energy issues are most often carried out on the basis of time series, written in general form by the following expressions:

$$
\begin{aligned}
& P(t)=a_{0}+a_{1} t+a_{2} \sin \left(\omega_{2} t+\phi_{2}\right)+ \\
& +a_{3} \sin \left(\omega_{3} t+\phi_{3}\right)
\end{aligned}
$$

where $a_{0}$ is the constant component; $a_{n}$ is the amplitude; $\omega$ is the frequency; $\varphi$ is the phase shift.

The average model error is defined as the average value of the model deviation from the actual data for the entire sample:

$$
\delta=\frac{\left|P_{\mathrm{act}}-P_{\mathrm{mod}}\right|}{\left|P_{\mathrm{act}}\right|} 100 \%,
$$

where $P_{\text {act }}$ is the actual power value, MW; $P_{\text {mod }}$ is the value of power consumption, obtained using the model, MW.

A time series reflecting a change in power consumption always contains a trend showing steady systematic changes and a periodic component - seasonal fluctuations relative to the trend. To obtain its approximate model, one can apply the discrete Fourier transform (DFT).

After applying the DFT, an array of complex numbers was obtained, each of which contains information about the corresponding harmonic of the original time series.
The phases of selected harmonics can be obtained from the phase spectrum, and the general model of power consumption is characterized by the equation:

$$
\begin{aligned}
& P=18.95+0.0043 t+8.8 \sin (0.5237 t+1.009)+ \\
& +2.59 \sin (1.047 t+0.785)
\end{aligned} .
$$

The coefficients of the time series can be selected both expertly and using various methods. Within the framework of solving problems related to power consumption modeling, the application of three methods for finding optimal coefficients for the time series configuration was evaluated: the gradient method, particle digging method and bee digging method. To automate the selection process, a software implementation of the "Prediction" block has been developed, which allows determining time series coefficients based on the listed methods.

When analyzing power consumption using a time series by asking initial approximations, it is possible to reduce the modeling error using the gradient optimization method. This method will begin the process with the solution found by the DFT, and then improve the model, reducing its average error. The resulting model is characterized by the equation:

$$
\begin{aligned}
& P=18.95+0.0048 t+8.8 \sin (0.5239 t+1.009)+ \\
& +2.59 \sin (1.047 t+0.785)
\end{aligned}
$$

The gradient method is sensitive to initial approximations that may affect the resulting solution, and, therefore, the modeling error. To reduce the error, the use of two methods of artificial intelligence was considered: a swarm of bEPS and a swarm of particles. The methods of swarm intelligences describe the collective behavior of various objects, each of which performs a number of simple functions, while interacting with other objects. The algorithm of swarm intelligence can be represented as a mathematical system:

$$
S \cdot I=\{\mathrm{S}, \mathrm{M}, \mathrm{A}, \mathrm{P}, \mathrm{I}, \mathrm{O}\},
$$

where $S$ is many agents; $\mathrm{M}$ is an object intended for the exchange of experience between agents (most often it is a certain matrix or vector to which all agents of the swarm have access and which is used in A); A are the rules of creation, modification, behavior of agents; $\mathrm{P}$ are parameters that are used in formulas from A;

$$
I=\left\{I_{1}, I_{\mathrm{fb}}\right\},
$$

$I_{1}$ is the system input to which the objective function and restrictions are applied; $I_{\mathrm{fb}}$ is input for feedback;

$$
O=\left\{O_{1}, O_{\mathrm{fb}}\right\}
$$

$O_{1}$ is output (the best-found solution to the problem); $O_{\mathrm{fb}}$ is output for feedback.

The model obtained by the particle swarm method is described by the following equation: 


$$
\begin{aligned}
& P=18.9+0.0047 t+2.49 \sin (5.2382 t+2.135)+ \\
& +8.59 \sin (5.67 t+2.172)
\end{aligned}
$$

The model obtained by the particle swarm method is represented by the equation:

$$
\begin{aligned}
& P=19.25-0.0022 t+7.48 \sin (6.8 t+0.61)- \\
& -0.11 \sin (4.57 t+0.25)
\end{aligned}
$$

Comparison of the implemented methods is shown in table 4.

From table 4 it can be seen that the most accurate was the model obtained using the particle swarm method, while the swarm of bEPS showed the biggest error. It should be noted that in the absence of information for two years, all models showed a good ability to recover data.

Table 4. Time series coefficients and average model error.

\begin{tabular}{|l|c|c|c|c|}
\hline Coefficients & DFT & $\begin{array}{c}\text { DFT+ } \\
\text { Gradient }\end{array}$ & $\begin{array}{c}\text { Swarm of } \\
\text { particles }\end{array}$ & $\begin{array}{c}\text { Swarm of } \\
\text { bEPS }\end{array}$ \\
\hline$a_{0}, \mathrm{MW}$ & 18.95 & 18.95 & 18.9 & 19.25 \\
\hline$a_{1}, \mathrm{MW}$ & 0.0043 & 0.0048 & 0.0047 & -0.0022 \\
\hline$a_{2}, \mathrm{MW}$ & 8.8 & 8.8 & 2.49 & 7.48 \\
\hline$\omega_{2}, \mathrm{~Hz}$ & 0.5237 & 0.5239 & 5.2382 & 6.8 \\
\hline$\varphi_{2},{ }^{\circ}$ & 1.009 & 1.009 & 2.135 & 0.61 \\
\hline$a_{3}, \mathrm{MW}$ & 2.59 & 2.59 & 8.59 & -0.11 \\
\hline$\omega_{3}, \mathrm{~Hz}$ & 1.047 & 1.047 & 5.76 & 4.57 \\
\hline$\varphi_{3},{ }^{\circ}$ & 0.785 & 0.785 & 2.172 & 0.25 \\
\hline$\delta, \%$ & 6.95 & 6.94 & 6.8 & 11.38 \\
\hline
\end{tabular}

To verify the universality of the considered methods for selecting coefficients, an additional object was considered - the unified energy system of Siberia (UES of Siberia), for which similar calculations were carried out. Comparative results of calculations for two objects are shown in table 5 .

Table 5. Average model errors for different EPS, in percent.

\begin{tabular}{|l|c|c|c|c|}
\hline $\begin{array}{l}\text { Power } \\
\text { grid }\end{array}$ & DFT & $\begin{array}{c}\text { DFT+G } \\
\text { radient }\end{array}$ & $\begin{array}{c}\text { Swarm of } \\
\text { particles }\end{array}$ & $\begin{array}{c}\text { Swarm } \\
\text { of bEPS }\end{array}$ \\
\hline $\begin{array}{l}\text { EPS } \\
\text { Pamir }\end{array}$ & 6.5 & 6.94 & 6.8 & 11.4 \\
\hline $\begin{array}{l}\text { UES } \\
\text { Siberia }\end{array}$ & 4.5 & 4 & 2.38 & 10.8 \\
\hline
\end{tabular}

Thus, for the considered objects, the adequacy of the methods is equivalent, i.e. the particle swarm method gives the smallest error, and the swarm of the bee's method gives the greatest error. The model created using DFT shows a satisfactory error, which is significantly reduced by the gradient optimization performed sequentially with the DFT.

The next task of the study of a simulation model development was to determine the load graphs in each node of the power system for analyzing the modes of its operation, taking into account the changes in parameters over time. In this case, the initial data were measurements of daily load graphs on regime days (winter maximum and summer minimum) for all substations of the Pamir power grid.

As a result of the comparison, the dependences of changes in hourly capacities and their time shift are obtained:

$$
\begin{aligned}
& P_{j i}=P_{\mathrm{S} . i} \frac{\left(P_{\mathrm{W} . i}-P_{\mathrm{S} . i}\right)}{5}(j-1) \\
& T_{j i}=T_{\mathrm{S} . i} \frac{\left(T_{\mathrm{W} . i}-T_{\mathrm{s} . i}\right)}{5}(j-1) .
\end{aligned}
$$

where $j$ is month, $i$ is the day time.

The derived law of changing the configuration of the load graph allows one to determine the load power in every hour of any day (month) in each node of the load of the power system, which makes it possible to carry out simulation calculations not of the instantaneous values of normal EPS modes, but taking into account the time factor.

A model of the Pamir power system was created in the Eurostag PVC, daily power generation and load schedule. Simulation of load graphs at each node allows simulating any modes of the electric power system depending on water resources.

\section{Imitations modeling of electric consumption and load schedules of EPS}

To simulate the joint control of the HPP cascade in the power system based on the transit flow for them, the functional capabilities of the Eurostag RVC were used to calculate the normal conditions. The maximum power limits developed in the speed control macro-model for the Pamir-1 and Khorog HPPs were used.

To check the correct functioning of the developed model, verification was carried out by testing macromodels at various water consumption values, calculated idle discharges, and stations through turbines, station power, and each hydraulic unit power at specified water consumption, also taking into account the time of wave arrival.

As a result of the calculations, an unacceptable voltage drop was detected in some narrow power systems, which corresponds to the real situation in the Pamir power system

\section{Conclusion}

The performed analysis of the existing methods and approaches to the study of operating modes of power systems with cascading hydroelectric power plants showed that the existing tools do not fully provide the simulation calculations and decision-making on EPS modes planning taking into account their features. A mathematical model of a hydroelectric power plant cascade has been developed, which takes into account the hydraulic connections during calculations of electric 
modes, which increases the efficiency of the hydro resources usage. The model of power consumption of the load graph was created using the methods of artificial intelligence, which allows simulation modeling of changes in power at each node at any time with discrete hour, day, and month. The simulation results confirm the adequacy of the model obtained, which allows it to be used in solving related problems of optimal water flow through the hydraulic system, taking into account hydrological limitations and external influences.

\section{References}

1. Yu.M. Sidorkin, A.G. Rusina, M.Sh. Misrikhanov, T.A. Filippova, Hydropower: studies for universities, 640 (2012)

2. O.V. Petinov, E.F. Shcherbakov, Testing of electrical apparatus, 215 (1985)

3. V.A. Dulin, Methods for studying the reliability of low-voltage devices, 152 (1970)

4. T.T. Namitokov, Testing of low voltage apparatus, 248 (1985)

5. M.G. Koblenz, Study of electrical wear resistance power contacts of contactors when operating in intermittent mode, 59-71 (1962)

6. E.A. Konyukhova, Reliability of power supply to industrial enterprises, 92 (2001)

7. V.V. Shevchenko, E.I. Gracheva, Determination of electric power losses in shop networks with voltage up to $1000 \mathrm{~V}$, Industrial power engineering, 10, 3335 (2001)

8. Yu.S. Zhelezko, A.V. Artemyev, O.V. Savchenko, Calculation, analysis and rationing of electricity losses in electric networks (2003)

9. O.V. Fedorov, Assessment of influence parameters of electric equipment at a size of losses the electric power in intra factory networks of low voltage, 2nd Int. Conf. on Industrial Engineering, Applications and Manufacturing, CFP16F42-ART (2016) DOI: 10.1109/ICIEAM.2016.7911463

10. G.V. Butkevich, N.A. Belkin, N.A. Vedeshenkov, Electric erosion of high-current contacts and electrodes, 256 (1978)

11. A.N. Shpiganovich, A.A. Shpiganovich, E.P. Zatsepin, Features of the functioning multi-level power supply systems, News from higher educational institutions of the Black Earth Region, 3(53), 12-24 (2018)

12. A.N. Shpiganovich, A.A. Shpiganovich, To assess the reliability parameters of the equipment for power supply systems, News of the higher educational institutions of the Black Earth Region, 4(46), 48-56 (2016)

13. E.I. Gracheva, N.A. Kopytova, Analysis structure of systems shop power supply of the enterprises the machine-building industry, News of higher educational institutions. Power problems, 5/6, 73-78 (2011)

14. R. Holm, Electric contacts, 456 (1978)

15. E.I. Gracheva, A.R. Safin, A.V. Shagidullin, Modeling of the influence changes in electrical equipment parameters on the value of the equivalent resistance the intrashop power supply systems, Elektrika, 7, 2-6 (2013) 